\title{
Letters
}

Website: bmj.com

Email: letters@bmj.com

\section{Patients' denial of disease may pose difficulty for achieving informed consent}

EDITOR-The 1998 Data Protection Act and the General Medical Council's guidance on confidentiality have resulted in uncertainty about whether patient consent is necessary to fulfil statutory requirements for fair and lawful processing of personal data such as the identifiable health information collected by cancer registries. ${ }^{12} \mathrm{~A}$ regulation is expected under the Health and Social Care Act 2001 for England and Wales, while a consultation process is ongoing in Scotland and Northern Ireland, where health is a devolved matter.

If we wish to retain population based surveillance of cancer, the options include anonymisation of data, informed consent, statutory regulation under the 2001 act, or primary legislation to make cancer statutorily registrable, as for many infectious diseases. Anonymisation or pseudoanonymisation would render the data invalid, since identifiable data are required to ensure quality control, investigate cancer clusters, and perform survival analysis by linking cancer and death records. The cost and difficulty of administering informed consent and the unquantifiable bias in cancer information due to the incompleteness of obtaining consent have been highlighted. ${ }^{3}$

Denial of the disease among a subgroup of patients would compound the threat to the utility of health surveillance data from a requirement for patient consent. Denial is a recognised way of coping with bad news such as a cancer diagnosis and doctors may "collude" in denial to help the patient cope. ${ }^{4}$ Denial would prevent doctors from asking permission to record the diagnosis in a cancer registry.

An audit by retrospective case note review of all patients diagnosed with cancer of the lung, breast, colon, rectum, or ovary in Northern Ireland in 1996 average.

A $\mathbf{T}$ Gavin director

D Fitzpatrick biostatistician

R J Middleton data manager University of Belfast, Belfast BT12 6BJ

M P Coleman head Hygiene and Tropical Medicine, London WC1E 7HT Northern Ireland. 29.) www.gmc-uk.org/standards Oncol 2001;12:145-7. $(n=2222)$ shows that non-discussion of diagnosis was part of active patient management in 14\% of lung cancer patients, $9 \%$ of colorectal, $4 \%$ of breast cancer patients, and $7 \%$ of women with ovarian cancer (table). These patients tended to be older than

The actual figures for non-discussion could be higher, since in $28-55 \%$ of notes there was no record of such discussion. A questionnaire survey of 500 cancer patients diagnosed more recently (1998-9) in one part of Northern Ireland showed that even six months after diagnosis, $4 \%$ of patients still denied that they had cancer (M J Thompson, personal communication).

Requiring informed consent for cancer registration and patient denial of the diagnosis would cause further loss of data of some $4-14 \%$, depending on the cancer.

Northern Ireland Cancer Registry, Department of Epidemiology and Public Health, Queen's

Cancer and Public Health Unit, London School of

Competing interests: The Northern Ireland Cancer Registry acknowledges funding from the Department of Health, Social Services and Public Safety,

1 Data Protection Act 1998. London: HMSO, 1998. (Clause

2 General Medical Council. Confidentiality: protecting and providing information. London: GMC, 2000. Available at

3 Brewster DH, Coleman MP, Forman D, Roche M. Cancer information under threat: the case for legislation. Ann

4 Dunkel-Schetter C, Feinstein LG, Taylor SE, Falke RL. Patterns of coping with cancer. Health Psychol 1992;11:79-87.

Discussion of diagnosis of cancer with patient by type of cancer. Values are percentages unless stated otherwise

\begin{tabular}{lcccc} 
& Lung $(\mathbf{n}=\mathbf{6 7 0})$ & Colorectal $(\mathbf{n}=\mathbf{7 3 7})$ & Breast $(\mathbf{n}=\mathbf{6 7 8})$ & Ovary $(\mathbf{n}=\mathbf{1 3 7})$ \\
\hline Diagnosis: & & & & \\
\hline Discussed & 58 & 52 & 41 & 52 \\
\hline Not discussed & 14 & 9 & 4 & 7 \\
\hline Not recorded & 28 & 39 & 55 & 41 \\
\hline Average age of patient (years): & & & & 59 \\
\hline Cancer discussed & 67 & 66 & 58 & 72 \\
\hline Cancer not discussed & 72 & 74 & 69 & 59 \\
\hline
\end{tabular}

\section{Global Alliance on Vaccines and Immunizations}

\section{Save the Children UK had concerns about alliance that went further than report did}

Editon-We would like to dissociate ourselves from the views reported in Fleck's news item about the global initiative that seeks to save millions of children's lives by immunisation. ${ }^{1}$ We were involved in the design and analysis of a study that was facilitated, funded, and published jointly with Save the Children UK. The report looked at four countries' experience with the application process to the Global Alliance on Vaccines and Immunizations (GAVI) and their perceptions about funding for systems support. Save the Children UK had several concerns about the alliance that went much further than the report but unfortunately gave the impression that these stemmed from the report.

Specifically, we wish to draw attention to four points.

Firstly, the study did not criticise the global alliance "for including managers from pharmaceutical companies on its governing board"; it made no comment on "a potential conflict of interest," or on the "the risk of commercial, product-oriented pressure."

Secondly, the reference to the initiative having failed to "ensure that additional resources were provided to countries" is an error. An innovative feature of the global alliance is that it did provide additional resources.

Thirdly, the study made no suggestion that such schemes could create "markets for costly new vaccines while doing little to tackle the biggest killer diseases." Diseases that are prevented by vaccination are among the big killers in poor countries.

Fourthly, the report did not say that "Ghana was given only 10 days to decide whether to accept a new hi tech vaccine for hepatitis B without any evidence that this was actually needed." All four countries welcomed the opportunity to introduce hepatitis $\mathrm{B}$ vaccine. Some respondents in Ghana expressed concern about the introduction of Haemophilus influenzae type B vaccine.

After the initial press release in Geneva on 15 January 2002, Save the Children UK issued the following statement: "The report is based on country-specific research conducted by the London School of Hygiene and Tropical Medicine and facilitated, funded and published jointly with Save the Children UK.... The media documents and statements of Save the Children UK 
therefore represent the considered views of that organisation alone and not those of the London School of Hygiene and Tropical Medicine. Save the Children UK regrets any confusion it may have inadvertently created between its critique of GAVI and the analysis produced by the London School of Hygiene and Tropical Medicine."

Gill Walt professor of international health policy gill.walt@lshtm.ac.uk

Ruairi Brugha senior lecturer in public health Mary Starling independent consultant London School of Hygiene and Tropical Medicine, Department of Public Health and Policy, Health Policy Unit, London WC1E 7HT

1 Fleck F. Children's charity criticises global immunisation initiative. BMJ 2002;324:129. (19 January.)

\section{Vaccine promotion is circumventing market forces}

EDITOR-Save the Children UK has noted the paradox of having vaccine manufacturers recommend the use of vaccines in developing countries-the paradox of the seller dictating demand.

In a market economy buyers evaluate the cost against benefit. If buyers refuse to buy then prices come down. The case of vaccine manufacturers is unique-they have broken loose from these market imperatives, using a subtle form of blackmail. They have convinced organisations such as the World Health Organization that new vaccine research can be expected only if good returns are ensured. The onus of showing cost benefit has shifted from the manufacturer to the consumer-organisations such as the WHO. Two things that support the charity's findings are, firstly, exaggerating benefits and, secondly, promoting vaccines that are not needed.

As an example of exaggerating benefits Miller (of the WHO's children's vaccine initiative) and Kane suggest that a quarter of carriers of hepatitis B in India die at age $45 .{ }^{1}$ For this they rely on the incidence of hepatocellular carcinoma in Taiwanese males (495 cases per 100000 carrier years). ${ }^{2}$ This ignores the statement in the report that this incidence is three or four times that in women. The real incidence in Taiwan works out at around 320. In Montreal no cases of hepatocellular carcinoma occurred, although 17 would have been expected. ${ }^{3}$ Selectively using figures for Taiwanese males to project the dangers of hepatitis $\mathrm{B}$ on to the world's population grossly exaggerates those dangers.

Then there is the promotion of vaccines that are not needed. Nossal recommended giving four doses of Haemophilus influenzae type $b$ vaccine to each year's birth cohort so that the price comes down. ${ }^{4}$ India is home to a quarter of that birth cohort. We have shown the existence of natural immunity to $H$ influenzae type $\mathrm{b}$ in Indian infants. ${ }^{5}$ The vaccine is not routinely used here at present, and thus Nossal is suggesting that we use the vaccine so that its price can come down in the West.

Doctors think that because of vaccines' societal benefits vaccine manufacturers must be considered differently from other pharmaceutical manufacturers. That, though, is to prejudge the issue. Not all vaccines will have the same societal benefits. Vaccine manufacturers cannot be defence and jury in arbitrating the issue. Organisations like the WHO must avoid the blandishments of vaccine manufacturers if they are to retain their credibility.

R K Ojha senior house officer

Jacob Abraham senior house officer

Meenakshi Khosla senior house officer

Jacob M Puliyel consultant paediatrician

Pulivel@vsnl.com

Department of Paediatrics, St Stephen's Hospital, Tis Hazari, Delhi 110054, India

1 Miller MA, Kane M. Routine hepatitis B immunisation in India: cost-effectiveness assessment. Indian J Pediat 2000;67:299-300.

2 Beasley RP. Hepatitis B virus. The major aetiology of hepatocellular carcinoma. Cancer 1988;61:1942-56.

3 Villeneuve J-P, Desrochers M, Infante-Rivard C, Willems B, Raymond G, Bourcier M, et al A follow up study of asympomatic hepatis B surface antigen-positive carriers in Montreal. Gastroenterology 1994;106:1000-5.

Nossal G. Living up to the legacy. Nature Med 1998:5:475-6.

Agar, Abass FA. Natural immunity to

Puliyel JM, Agarwal KS, Abass FA. Natural immunity to infancy in Indian children Vaccin $2001 ; 19: 4592-4$.

\section{Fifth revision of Declaration of Helsinki}

\section{Clause 29 forbids trials from using} placebos when effective treatment exists

EDIToR-I was delighted by the new clause 29 in the revised Declaration of Helsinki, which forbids clinical trials comparing drugs against no treatment when an effective treatment exists. I was dismayed that the World Medical Association was retreating from this position. ${ }^{1}$ From reading Hirsch and Guess's piece in the article about the latest revision of the Declaration of Helsinki, I am concerned that opposition from the pharmaceutical industry may lead to further revision. ${ }^{2}$

I spent two years on a multicentre research ethics committee, which saw many proposals for trials of active versus no treatment. In some of these cases an effective treatment already existed. I think it wrong to ask people who have come seeking treatment to do without it for the sake of research. People come to doctors for help, not to act as experimental subjects either for scientific curiosity or for drug regulation.

For example, a trial was proposed of a drug versus placebo in symptomatic benign prostatic hyperplasia. Men in the trial were to take the placebo for more than a year. We were told that this drug was "equivalent" to another established treatment. What would happen to these men if they were not in the trial? Surely they would be treated.

The patient information sheet stated that the drug was available in many other countries in $x \mathrm{mg}$ twice daily form, that a new $2 x \mathrm{mg}$ formulation was being studied and might show the same effectiveness as the original formulation, and that its effects compared with the effects of dummy capsules had to be tested. This struck me as a complete non sequitur. What is necessary is to compare $2 x \mathrm{mg}$ with $x \mathrm{mg}$ twice daily. There was no need to test $2 x \mathrm{mg}$ against no treatment at all.

Another proposal was for a trial of a drug for Paget's disease of the bone. The applicants had already shown that the drug was better than placebo with smaller doses in a larger trial. This was a six month trial with a bone biopsy. Should we really be asking patients to do this?

I can understand that clause 29 as currently stated might be interpreted as preventing trials in environments where the best current clinical methods are not available because of their cost. It could be amended to permit such trials without allowing patients to be lured into foregoing proved effective treatment where it exists and is accessible to them.

J M Bland professor of medical statistics Department of Public Health Sciences, St George's Hospital Medical School, London SW17 0RE mbland@sghms.ac.uk

1 Ferriman A. World Medical Association clarifies rules on placebo controlled trials. BMJ 2001;323:825

2 Tollman SM, Bastian H, Doll R, Hirsch LJ, Guess HA. What are the effects of the fifth revision of the Declaration of Helsinki? BMJ 200 1;323:1417-23. (15 December.)

3 Bland JM. WMA should not retreat on use of placebos. BMJ 2002;324:240. (26 January.)

\section{Ethics and money are not good} bedfellows

EDITOR-Clause 30 of the latest revision of the Declaration of Helsinki says: "At the conclusion of the study, every patient entered into the study should be assured of access to the best proven prophylactic, diagnostic and therapeutic methods identified by the study."

Recently, my unit has participated in a trial comparing continuous subcutaneous insulin infusions (insulin pump therapy) with multiple daily injections in type 1 diabetes. At the end of the trial more than $80 \%$ of the participants chose to continue having the continuous infusions, which they perceived were of more benefit to them.

At present these infusions are not available to NHS patients, but locally more than 50 patients have used their own money to buy this treatment while remaining NHS patients. In addition to the cost of purchasing a pump (£2000), however, there are also running costs of roughly $£ 1000$ each year. Although the National Institute for Clinical Excellence intends to examine these continuous infusions, any decision is likely to be delayed. Furthermore, seemingly no new money is available to pay for novel treatments and something else will have to go.

The question is who should pay for the ongoing costs-secondary care, which initiated the treatment; the patients; or primary care? If primary care, should it be involved at the outset of clinical trials in terms of being willing to continue supporting new treatments as suggested by the above declaration?

Data from randomised controlled clinical trials may indicate that one treatment is 
better than another, but there is the extra dimension of patients being able to choose their treatment after participating in a clinical trial. Who decides, and should patients have a choice?

David Kerr consultant physician

Bournemouth Diabetes and Endocrine Centre,

Bournemouth BH7 7DL

david.kerr@rbch-tr.swest.nhs.uk

1 Tollman SM, Bastian H, Doll R, Hirsch LJ, Guess HA. What are the effects of the fifth revision of the Declaration of Helsinki? BMJ 2001;323:1417-23. (15 December.)

\section{Bipolar affective disorder}

\section{Suicide statistics were misleading}

EDITOR-Morriss et al say that the lifetime prevalence of suicide attempts in people with bipolar affective disorder is $50 \%$ and that this figure could be reduced by treatment. ${ }^{1}$ I have two comments.

Firstly, the lifetime prevalence of completed suicides among bipolar patients is of an order of magnitude less than $50 \%$ and is not significantly different from that of people suffering from schizophrenia, borderline personality disorder, alcohol dependency, or affective disorders other than bipolar illness. ${ }^{2}$ Secondly, there is no evidence that treatment prevents suicide in patients with any mental disorder. ${ }^{34}$

Morriss et al are not the first to dramatise the need for funding one or another project in health service delivery by quoting misleading statistics on suicide. The temptation to do so should, however, have been resisted.

Thomas J P Verberne clinical neuropsychologist (retired)

14 Crampton Crescent, Rosanna, Victoria 3084 Australia

verberne@melbpc.org.au

1 Morriss R, Marshall M, Harris A. BMJ 2002;324:61-62 Bipolar affective disorder left out in the cold: too late for the national service framework but local initiatives may be possible. (12 January.)

2 Inskip HM, Harris C, Barraclough, B. Lifetime risk of suicide for affective disorder, alcoholism and schizophrenia. BrJ Psychiatry 1998;172:35-7.

3 Baldessarini RJ, Jamison KR. Summary and conclusions: Effects of medical interventions on suicidal behavior. J Clin Psychiatry 1999;60(suppl 2):117-22.

4 Khan A, Warner HA, Brown WA. Symptom reduction and suicide risk in patients treated with placebo in antidepressant clinical trials. Arch Gen Psychiatry 2000;57:311-7.

\section{Author's reply}

EDITOR-We carefully worded our paper to discuss the effects of management on suicide attempts in bipolar affective disorder, not suicide, precisely because there is little evidence that treatment prevents suicide in patients with any mental disorder. We did not make any claims at all about suicide in bipolar affective disorder.

There is evidence that treatment reduces suicide attempts in bipolar affective disorder. Retrospective and prospective follow up in 5233 patient years of observation suggested that maintenance treatment with lithium was associated with a highly significant 6.4 - to 7.5fold reduction in suicide attempts in patients with bipolar affective disorder. ${ }^{1}$ Nevertheless, there is some evidence that suicide in patients with bipolar affective disorder is associated with suboptimal treatment.

A psychological autopsy study of all 31 suicide victims with bipolar affective disorder in Finland in one year found that 12 (39\%) patients had expressed their suicidal intent to healthcare personnel in the previous three months; only $10(32 \%)$ patients were prescribed lithium, and only three of 24 patients with major depression at the time of suicide had received adequate doses of antidepressants. ${ }^{2}$ These data sug gest that some suicides in patients with bipolar affective disorder may be preventable with active management of the suicide risk, adequate treatment of the depressed phase of bipolar disorder with antidepressants, and maintenance treatment with lithium.

Richard Morriss professor of psychiatry

University of Liverpool, Liverpool L69 3BX rmorris@liverpool.ac.uk

\section{Tondo L, Baldessarini RJ, Hennen J, Floris G, Silvetti F, Tohen M. Lithium treatment and risk of suicidal behavio in bipolar disorder patients. I Clin Psychiatr in bipolar diso \\ 2 Isometsa ET, Henriksson MM, Aro HM, Lonnqvist JK. Sui- cide in bipolar disorder in Finland. Am J Psychiatr 1994;151:1020-4}

\section{First episode psychosis}

\section{Patients must be asked about suicidal} ideation and substance misuse

EDITOR-Lester's article on first episode psychosis is welcome, ${ }^{1}$ given that general practitioners have a low index of suspicion for the presence of psychosis and little confidence in diagnosing it. ${ }^{2}$ But the article omitted two essential considerations-namely, the need to ask about hallucinations and about the risk of self harm and of harm to others; these may be closely related when command hallucinations instruct the person to commit self harm or harm others.

Exploration of suicidal ideation (which may be independent of depression) is essential. Suicide is the chief cause of premature death among people with schizophrenia, with $4-13 \%$ of such people committing suicide and 25-50\% making a suicide attempt.

The risks may be further compounded by misuse of alcohol and drugs, precipitating impulsive self harm or harm to others. Identification of comorbid substance misuse may be crucial in managing this group, given the increased attendant risks and the strong association between first episode schizophrenia and substance misuse. ${ }^{3}$ Substance misuse is likely to be related to suicidal ideation and warrants early attention. ${ }^{45}$

Regrettably, little systematic study has been done of people with first episode psychosis, but the development of a positive trusting relationship with a single mental health key worker as early as possible is advisable. Probably the best results come when the person with schizophrenia and the key worker search for common ground. The key worker should avoid a premature confrontation about the explanatory model of the illness and deliver treatment in as flexible a manner as possible.

Andrew Sandor lecturer in social and community psychiatry

Royal Free and University College, Medical School, London N19 5NF

a.sandor@ucl.ac.uk

1 Lester H. 10-minute consultation. First episode psychosis BMJ 2001;323:1408. (15 December.)

2 Lincoln C, McGorry P. Who cares? Pathways to psychiatric care for young people experiencing a first episode of psychosis. Psychiatr Serv 1995;46:1166-71.

3 Hambrecht M, Hafner H. Substance and onset of schizophrenia. Biol Psychiatry 1996;40:1155-63.

4 Spencer E, Birchwood M, McGovern D. Management of Spencer E, Birchwood M, McGovern D. Management of first episode psyc

5 Kamali M, Kelly L, Gervin M, Browne S, Larkin C, O'Call M, Kelly L, Gervin M, Browne S, Larkin C, O Callaghan E.. The prevalence of comorbid substance in-pe and its inflence on suicidal ideation among in-patients with schizophrenia. Acta Psychiatr Scand

\section{GPs must assess patients' risk behaviour}

EDitor-Lester highlights the difficulty that doctors in primary care have in detecting psychosis in a 10 minute consultation. ${ }^{1}$ She gives good advice on the breadth of the assessment and the action to be taken. But self harm in psychosis is not mentioned. The government is aware of the risks of self harm and the risks to others posed by people with mental illness. The assessment of risk behaviour has a prominent place in the care programme approach in mental health practice. It is therefore equally important for general practitioners to assess their patients' level of risk as part of the 10 minute consultation.

Mortality from unnatural causes is higher in people with severe mental illnesses such as psychosis, mood disorders, and personality disorders. People with psychosis are at risk to themselves and others because of their potential to act in response to command hallucinations or delusional beliefs or because of feelings of guilt over past actions. Harris refers to reports of the risk of suicide in schizophrenia being greatest at the inception of the illness-precisely the time when the patient may present to primary care. ${ }^{2}$ Therefore, inquiry about thoughts of self harm or harm to others must be an essential component of even the most pressured assessment of a person's mental state in primary care.

Ken Courtenay specialist registrar, psychiatry Department of Psychiatry, St George's Hospital Medical School, London SW17 0RE

kcourten@sghms.ac.uk

1 Lester H. 10-minute consultation: First episode psychosis. BMJ 2001;323:1408. (15 December.) 2 Harris EC, Barraclough B. Excess
order. BrJ Psychiatry 1998;11:53.

\section{Preimplantation genetic diagnosis for donor babies carries some harm}

EDITOR-Are the dangers in using preimplantation genetic diagnosis to create donor babies as minimal as Boyle and Savulescu claim?' The concerns about "commodifica- 
tion" of donor babies are real. The fact that Kant's dictum was "never use people solely as a means" is not a reassurance, because these donor babies are solely means to an end (the successful treatment of a sick sibling).

To rebuff accusations of instrumentalism, parents have claimed that they wanted another child anyway. In the past, additional children gave the hope of providing a suitable donor for an older sibling, but this was only a chance. Today, preimplantation genetic diagnosis guarantees a tissue compatible donor, and this certainty impacts on the ethical quality of this decision.

Parents also risk psychological and physical dangers to the donor baby. Indeed, the Royal College of Obstetricians and Gynaecologists has expressed concern about the potential risks to both mother and child. $^{2}$

Because the volume of cord blood is small it is only effective in treating young children; an older child will need to be given a bone marrow transplant. Molly Nash has Fanconi's anaemia. ${ }^{1}$ People with this frequently have other organ abnormalities (particularly renal) and are more susceptible to cancers, especially leukaemias. In the future, Molly may ask Adam, her brother, for bone marrow to treat her leukaemia, or a kidney for her renal failure.

It is not known if, in choosing a certain tissue type, parents may be choosing to have a child who will later go on to have more illnesses and die earlier than a noncompatible child would.

In law, parents may consent to treatment on behalf of their sick children as proxy decision makers. Not only is it unethical for parents to consent to unnecessary tests or treatment that are not in the interests of the child but, as the law stands, there can be no legal justification for any non-therapeutic invasion of the bodily integrity of an incapacitated person.

Parents will naturally be distraught at the prospect of the death of a much loved child and will do almost anything to prevent that death. Does this really allow for free and informed consent when they choose to undertake preimplantation genetic diagnosis or in subsequent decisions involving the donor baby?

Sue Turner PhD student

Institute for the Study of Genetics, Biorisks and Society, University of Nottingham, Nottingham NG7 2RD

lqxsct@nottingham.ac.uk

1 Boyle RJ, Savulescu J. Ethics of using preimplantation genetic diagnosis to select a stem cell donor for an existing person. BMJ 2001;323:1240-3. (24 November.)

2 Kmietowicz Z. Doctors object to companies offering to store cord blood. BMJ 200 1;323:1203. (24 November.)

\section{Rehabilitation services remain important in multiple sclerosis}

EDITOR-Taylor's enthusiasm for the proposed "sale or return" arrangement for interferon beta seems ill informed. ${ }^{1}$ Given the variability of multiple sclerosis over time in individual patients, how is the success of treatment to be judged? Using historical controls, such as the Canadian cohort, requires the availability of detailed data to match controls to the current treatment criteria. $^{2}$

In making these choices, quality adjusted life years and similar utility measures are all we have, flawed as they are. A better debate is over the cut-off level. According to the National Institute for Clinical Excellence, the upper threshold for interventions judged to offer acceptable NHS value is about $£ 30000$ per quality adjusted life year. The institute has provided no justification for this figure, which is high when compared with that of many treatments already in use. The economic output of two residents of the United Kingdom, or the disposable income (over the poverty line) of many more, would be required to deliver each added year of life. This figure could be sustained for a few rarer diseases but would still infringe the "equal resources for equal need" rule of distributive justice.

The pharmaceuticals market is not a free market as it lacks important characteristics: availability of consumer information (on appropriate outcomes), competitive pricing, and a mechanism equivalent to consumer choice (choices on treatments and payment are made by third parties). The National Institute for Clinical Excellence should offer such a mechanism but is weak and further enfeebled by this risk sharing proposal. The Drug and Therapeutics Bulletin performs more robust independent assessments, often contrary to those by the institute. ${ }^{34}$ The recent examples of riluzole and acetylcholinesterase inhibitors, with their meagre benefits, indicate that the new drugs for neurological diseases are just too expensive.

Drug companies control information and are now more secretive than governments. They put the best gloss on their results, such as reporting relative reduction rather than absolute benefit. Research should be removed from their control through independent third parties choosing researchers because of the quality of their research, not the results. All research should be openly registered, with an estimated date of publication to guarantee openness further. Until that happens all NHS and university staff should be required to register their research projects as part of governance.

Patients with multiple sclerosis do indeed need treatments that work. But these are high quality rehabilitation services (though they are not glamorous or profitable), which should be available to all, including patients who might use the new treatments as well-after all, they will not abolish disability.

Richard Richards consultant public health physician North Nottinghamshire Health Authority,

Rainworth, Mansfield NG21 0ER

Richardrichards@nnotts-ha.nhs.uk

1 Taylor D. Funding medicines for people with multiple sclerosis. BMJ 2001:323:1379-80. (15 December)

2 Weinshenker BG, Bass B, Rice GP, Noseworthy J, Carriere W, Baskerville J, et al. The natural history of multiple sclerosis: a geographically based study. I. Clinical course and disability. Brain 1989;112:133-46.

3 Is sibutramine more than a slim hope? Drug Ther Bull 2001;39:89-91

4 Response to Drug and Therapeutics Bulletin-sibutramine. Available at: www.nice.org.uk/article.asp?a $=25608$

\section{Postoperative chemoradiotherapy helps in gastric adenocarcinoma}

EditoR-Bowles and Benjamin's clinical review of cancer of the stomach and pancreas omits any consideration of postoperative chemoradiotherapy for patients with completely resected adenocarcinoma of the stomach. ${ }^{1}$ The Southwest Oncology Group has shown significant improvement in overall survival in patients who received postoperative chemoradiotherapy. ${ }^{23}$ The proportion of patients surviving three years after surgery and chemoradiotherapy was $50 \%$, compared with $41 \%$ in patients who had surgery alone.

This magnitude of survival benefit is equivalent to gains reported with preoperative chemotherapy in oesophageal cancer" investigators reported survival at two years as being $43 \%$ for patients who had chemotherapy and surgery, compared with $34 \%$ for those who had surgery alone. They concluded that neoadjuvant chemotherapy followed by surgery should become standard treatment in trials in this group of patients.

Presumably neoadjuvant chemotherapy should also be considered as standard for patients with oesophageal cancer, for whom such trials are unavailable. In order to have the opportunity for equivalent survival gains, patients with completely resected gastric adenocarcinoma should have a clinical oncology assessment for consideration of postoperative chemoradiotherapy.

Kenneth S Wilson consultant in medical oncology British Columbia Cancer Agency, Vancouver Island Centre, Victoria, British Columbia, Canada V8R 6V5

KWilson@bccancer.bc.ca

1 Bowles MJ, Benjamin IS. ABC of the upper gastrointestin tract: Cancer of the stomach and pancreas. BMJ tract: Cancer of the stomach

2 Macdonald JS, Smalley S, Benedetti J, Estes N, Haller DG Ajani JA, et al. Postoperative combined radiation and chemotherapy improves disease-free survival and overall survival in resected adenocarcinoma of the stomach and G.E. junction. Results of intergroup study INT-0116 (SWOG 9008). Proc Am Soc Clin Oncol 2000;plenary abstract 1

3 Macdonald JS, Smalley SR, Benedetti J, Hundahl SA, Estes NC, Stemmermann GN, et al. Chemoradiotherapy after surgery compared with surgery alone for adenocarcinoma of the stomach or gastroesophageal junction. $N$ Engl J Med 2001;345:725-30.

4 Clark PI. Neoadjuvant chemotherapy in oesophageal cancer. Eur J Cancer 2001;37 (suppl 6):140.

\section{Endoscopy is useful during percutaneous tracheostomy}

EDITOR-Percutaneous tracheostomy is now well established in intensive care units in the United Kingdom. ${ }^{1}$ Routine use of endoscopy during this procedure is less well established, and Susanto's comment that most percutaneous tracheostomies are done 
under endoscopic guidance requires comment. ${ }^{2} \mathrm{~A}$ survey of intensive care units in the United Kingdom found that less than one third of units routinely used fibreoptic endoscopy during the procedure.

We reviewed seven papers published in 2000 or 2001 that either compared percutaneous tracheostomy with surgical tracheostomy or compared different methods of percutaneous tracheostomy. In only two of these studies was endoscopy routinely used.

The use of endoscopy may decrease as experience of the technique increases. In one prospective study of 100 cases endoscopy was used for the first 14 cases and then abandoned as a routine procedure. ${ }^{3}$

We use continuous fibreoptic endoscopy with a video display for all percutaneous tracheostomies. This allows assessment of the airway before the procedure and detection of complications during the procedure. How can early, initially subclinical, complications be detected if they are not looked for? Complications may occur because of components of the procedure that are common to many other techniques, such as intratracheal placement of the needle and guidewire, or because of the method of dilating the tract. Continuous endoscopic inspection may allow a distinction to be made between these complications.

Future studies of percutaneous tracheostomy should include endoscopy as a routine component of the procedure.

Paul Jefferson consultant in anaesthetics and intensive care

p.jefferson@dgri.scot.nhs.uk

David R Ball consultant in anaesthetics and intensive care

Dumfries and Galloway Royal Infirmary, Dumfries DG1 4AP

1 Cooper RM. Use and safety of percutaneous tracheostomy in intensive care. Report of a postal survey of ICU practice. Anaesthesia 1998;53:1209-12

2 Susanto I. Comparing percutaneous tracheostomy with open surgical tracheostomy. BMJ 2002;324:3-4. (5 January.

3 Velmahos GC, Gomez H, Boicey CM, Demetriades D. Bedside percutaneous tracheostomy: prospective evaluation of a modification of the current tect World J Surg 2000;24:1109-15.

\section{Income inequality and population health}

Better measures of social differentiation and hierarchy are needed

EDITOR-Mackenbach's editorial reads like an obituary for the hypothesis that income inequality is related to population health. ${ }^{1}$ But a substantial body of evidence of such a relation has accumulated over the past 20 years, not only in the United States but also in Brazil, Russia, Taiwan, and England. Attempts to explain away this relation are rarely relevant to more than one of the many contexts in which it occurs.

The fact that health is more closely related to income in developed societies than to differences in income between them suggests effects of relative income or social status. ${ }^{2}$ But if income distribution has its main effect through differences in social sta- tus, and individual income (or education) is a proxy for individual social status, controlling income distribution for individual income makes little sense. ${ }^{3}$ It is a difference without a distinction, and more status equality is likely to improve average health.

As with individual income, the assumption that the median income of small areas measures material consumption rather than social relativities is unwarranted. Differences in median income between small areas are components of the income inequality of the larger areas. Choosing smaller areas converts variance, which would be income inequality in larger areas, into what is naively taken to be absolute income. Hence associations between income inequality and health tend to be strongest in larger areas and weakest in smaller areas, while the opposite is true of associations between median income and health.

Poor social affiliations and low status carry high population attributable risks. More unequal societies not only suffer more relative deprivation but tend to have lower rates of trust and of community involvement and-as over 40 studies show-more violence. More unequal societies will be more differentiated by social rank into relations of dominance and subordination and less able to enjoy more egalitarian and inclusive relations consistent with higher social capital and less class and racial prejudice. ${ }^{4}$ The links with violence show that inequality has psychosocial effects, and, given the powerful association between violence and other causes of death, critics should tread with caution.

Income may work better as a proxy for difference in social status in the United States than elsewhere. European differences in status ranking may be smaller and need more subtle markers. To test hypotheses that are fundamentally about differences in social status we need better measures of social differentiation and the importance of hierarchy in a society. The social dominance orientation scale might be a good place to start.

Richard Wilkinson professor of social epidemiology Division of Public Health Sciences, University of Nottingham Medical School, Nottingham NG7 2UH

Richard.Wilkinson@Nottingham.ac.uk

1 Mackenbach JP. Income inequality and population health. BMJ 2002;324:1-2. (5 January.)

Wilk $\mathrm{RG}$. Health inequalites: material standards? BMJ 1997;314:591-5.

3 Marmot M, Wilkinson RG. Psychosocial and materia pathways in the relation between income and health: response to Lynch et al. BMJ 2001;322:1233-6.

4 Wilkinson RG. Mind the gap: hierarchies, health and human evolution. London: Weidenfeld \& Nicolson, 2000.

5 Sidanius J, Pratto F. Social dominance: an intergroup theory of social hierarchy and oppression. Cambridge: Cambridge University Press, 1999.

\section{Hierarchy and health are related}

EDITOR-Mackenbach's editorial and the accompanying four studies suggest that individual income rather than income distribution is the important determinant of population health.

The studies presented do not deny a relation between hierarchy and health, but the results suggest that income distribution may not always be a good measure of that hierarchy. Non-income aspects of social rankings operating in specific cultures may overpower single economic measures such as income distribution. In addition, as the Japanese study suggests, high levels of inequality may be required before income effects are shown. Given that a perfect measure of inequality or hierarchy does not currently exist, however, the lack of such a measure does not refute the possibility of an important relation between hierarchy and health.

In Japan the poorest region (Okinawa) seems to have the lowest mortality, ${ }^{2}$ which is at odds with Mackenbach's individual income hypothesis. The Japanese study of Shibuya et al looked at self rated health, but this measure has been validated as related to mortality measures by only one study in Japan, compared with 13 studies of American populations. ${ }^{3}$ Only $0.8 \%$ of Shibuya et al's sample rated their health as poor, in contrast to studies in other populations with higher rates, such as $4.8 \%$ in an American study.

The Copenhagen study confirms previous evidence. Denmark is the only rich country that has worse health, as measured by life expectancy, than the United States (the world's richest and most powerful country). Unlike the United States government, the Danish government has an official website (www.sum.dk/health/sider/print.htm) that calls attention to its relatively poor health status compared with that of other European countries and to its not having had the same secular time improvements as other countries.

This site also shows Denmark's poor life expectancy ranking, an unusual admission by a country. A higher prevalence of smoking may not be a satisfactory explanation: Japan is the world's healthiest country when ranked by life expectancy but has the highest male smoking rates of any country in the Organisation for Economic Cooperation and Development.

If individual income, rather than its distribution, is so important then why does Kerala, one of India's poorest states, have a life expectancy approaching that of the United States? $?^{5}$ The key piece of evidence required to help convince the wealthy would be that the health of the richer is better where hierarchy is decreased and everyone shares more in the fruits of society.

Stephen Bezruchka affiliate associate professor Department of Health Services, School of Public Health and Community Medicine, University of Washington, Box 357660, Seattle, WA 98195-3576, USA

sabez@u.washington.edu

1 Mackenbach JP. Income inequality and population health BMJ 2002;324:1-2. (5 January.)

2 Cockerham WC, Hattori H, Yamori Y. The social gradient in life expectancy: the contrary case of Okinawa in Japan. Soc Sci Med 2000;51:115-22

3 Idler EL, Benyamini Y. Self-rated health and mortality: a review of twenty-seven community studies. J Health Soc Behav 1997;38:21-37.

4 Kawachi I, Kennedy BP, Glass R. Social capital and self-rated health: a contex 1999:89:1187-93.

5 Sen A. Development as freedom. New York: Knopf, 2000. 


\section{If only lottery winnings were randomly assigned}

EDITOR-The causal effect of income on health has important policy implications, and yet its identification is dogged by the problem of income not being randomly assigned. Researchers continue to ignore this, including Rodgers in his editorial, ${ }^{1}$ but the idea that the problem can be overcome by exploiting lottery winnings as a "natural experiment" is superficial because winners are not randomly selected from the population since playing is not a random event.

Although playing is popular, it is far from universal. The probability of winning is directly proportional to the number of tickets bought, so winners, on average, will be disproportionately heavy players.

Survey evidence suggests that players and non-players differ systematically in terms of their observable characteristics such as age, education, and sex. ${ }^{3}$ Indeed, expenditure survey data show that, compared with non-players, players insure less, smoke more, work less, have more modest pension provision, are more likely to live in social housing, have larger credit card debts, and save less. Controlling for all of these observable differences through matching or multivariate methods may well be possible, but considerable unobservable heterogeneity that would be difficult to control for would probably remain.

Data suggest that lottery players have higher rates of "time preference" than non-players do. In games in the United States most states offer jackpot winners the choice between $\$ x$ a year for the next 20 years or $\$ 10 x$ in cash today; most winners choose the latter even though the present value of the former far exceeds it at typical interest rates. This suggests that the time preference among players is high-higher than would be suggested by typical interest rates. This raises the problem that winners are more likely to be impatient people with a high time preference who have invested less than others in their health (by diet, exercise, not smoking, etc) throughout their lives.

It is important to know not only whether money matters but also when (if ever) it matters. Does having more money when we are young-perhaps money given by our parents-make for better health in the long run than having more money when we are old (and perhaps already sick)? Having lottery winnings randomly distributed would have been a useful way of answering important policy questions-if only winning were random

Ian Walker professor

Department of Economics, University of Warwick, Coventry CV4 7AL

i.walker@warwick.ac.uk

1 Rodgers, A. Income, health, and the National Lottery. BMJ 2001;323:1438-9. (22-29 December)

2 Osler M, Prescott E, Grønbæk M, Christensen U, Due P, Engholm G. Income inequality, individual income, and mortality in Danish adults: analysis of pooled data from mortality in Danish adults: analysis of pooled data
two cohort studies. BMJ 2002;324:13-6. (5 January.)

3 Farrell L, Walker I. The welfare effects of lotto: evidence

from the UK. J Public Economics 1999;72:99-120.

\section{Surgeons should beware of plans to print individual performance}

Editor-Before the NHS proceeds much further with the idea of publishing details of the performance of individual surgeons, note ought to be taken of experience in the United States, the country with most experience in the public release of such data. The main consequence will be a reluctance to treat riskier patients.

Since 1992 Pennsylvania has published a consumer guide to coronary artery bypass surgery; this lists annual risk adjusted mortality for all hospitals and surgeons providing such surgery in the state. Schneider and Epstein conducted a survey of cardiologists and cardiac surgeons to seek their views on its usefulness and limitations. ${ }^{2}$ Altogether, $59 \%$ of cardiologists reported increased difficulty in finding surgeons willing to perform coronary artery bypass surgery in severely ill patients who required it and $63 \%$ of the cardiac surgeons reported that they were less willing to operate on such patients.

Similarly, one study suggested that the movement of severely ill patients to an adjacent state had been a measurable effect of New York State's public reporting of data on coronary artery bypass surgery. ${ }^{3}$ Whereas this movement can occur in a consumer, privately funded, system, it is unclear where these patients would move to if faced with similar problems in the United Kingdom. Access to health care for seriously ill patients would probably be decreased, ultimately leading to a decrease in NHS costs-a byproduct that would be welcomed by the government

A further complicating factor is that operative mortality is always attributed to the surgeon. Thus the subtle but important influences of (in heart cases) cardiological management and referral, anaesthetic care, and intensive care resources are ignored. A recent editorial highlighted the importance of anaesthetic management in influencing surgical wound healing, which is arguably the commonest cause of postoperative morbidity, long hospital stays, and increased costs. ${ }^{4}$ These factors are some of those used to compare surgical outcome and yet may be outside surgical control. In other words, surgeons may be criticised for their postoperative morbidity when compared with their colleagues, but it may all be the fault of the anaesthetist.

Nicholas Pace consultant anaesthetist Western Infirmary, Glasgow G11 6NT np@blanefield.com

\footnotetext{
Vass A. Performance of individual surgeons to be published. BMJ 2002;324:189. (26 January.)

2 Schneider EC, Epstein AM. Influence of cardiac surger performance reports on referral practices and access to care. N Engl J Med 1996;335:251-6.

3 Omoigui NA, Miller DP, Brown KJ, Annan K, Cosgrove D 3rd, Lytle B, et al. Outmigration for coronary bypass surgery in an era of public dissemination of clinica outcomes. Circulation 1996;93:27-33.

4 Buggy D. Can anaesthetic management influence surgic wound healing? Lancet 2000:356:355-7.
}

\section{Open letter to the National Blood Service}

EdToR-Another invitation to give blood has arrived, bringing with it a now familiar wash of guilt. I have not given since last July, and I am not sure whether I shall ever do it again. My sister, whose rare blood group makes her contribution particularly valuable, will not go either, and for the same reasons.

We both had blood taken by someone who was not competent to do the job. We both suffered pain and extensive bruising. Giving blood is not pleasant but it should not leave the arm discoloured and sore from elbow to wrist for over a week. Our experience the previous time had been bad, but the second time, it was unacceptable.

I left a message informing the local service in Caernarfon, and their public relations woman called me back. She promised that she would make sure that the nurse responsible would ring me. I heard nothing. I rang the central London office and spoke to another woman who seemed to take my complaint seriously, although, she said, there was nothing she could do. She promised to fax the medical director without delay. Again, I heard nothing. Nobody, it seemed, was willing to accept responsibility.

Although inadequate skill of a particular phlebotomist is, presumably, a local issue, I believe that my experience highlights a wider problem with the blood service. Given that donors are needed, should not the service do its best to minimise the unpleasantness of the experience?

I have been giving blood for 30 years. Little has changed. There is no welcome, only a series of queues; staff do not introduce themselves, nobody takes care of novice donors, nobody takes any notice if a donor says her arm hurts (a reliable sign, I have discovered, that the needle has not been efficiently inserted). Donors are not treated as people-even less, as volunteers who should be encouraged.

But few people will put up with this sort of treatment nowadays. If donors can be persuaded to come, they are not likely to return. I have never been invited to give feedback on my experiences. It seems that the blood service does not want to know what happens to its donors: it did not follow up my calls, nor question why my sister did not return. I would feel reassured if I knew the local problem was being taken seriously and the phlebotomist had received further training, but I have no reason to believe any action has been taken. No wonder the NHS is short of blood.

Arabella Melville independent consultant for the NHS Bryn Derwen, 1 Osmond Terrace, Porthmadog. Gwynedd LL49 9AN

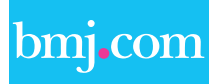

\section{Rapid responses}

Correspondence submitted electronically

is available on our website 